\title{
Pertunjukan Sandhur Tuban Refleksi Peralihan Masyarakat Agraris Menuju Budaya Urban
}

\author{
Rohmat, Djoko Prakosa \\ Sekolah Tinggi Kesenian Wilwatikta Surabaya \\ Klampis Anom II perum Wisma Mukti Sukolilo Surabaya 60117
}

\begin{abstract}
The Sandhur perfomance reflectsthe change of the agrarian societies to the urban culture. The text of performance contains hermeneutics code, proaretik code/the basic narrative action, semantic code, culture code, and simbolic code. The performance text can be intrepeted as a sign and symbol of the urban culture of the Tuban society lives. The relations of human, God, nature, and culture, are attached in the Sandhur structure of perfomance intact. Human being becomes part of the structure of living in a natural cycleswhich still exist in the cosmic unanimity.

In reading and describing the performance of Sandhur are used a qualitative approach. In this case researcher become the main instrument. The exposure of the natural phenomena performance refers to the model of ethnography. To understand the performance texts of Sandhur, researcher sharpen the interpretive analysis of the sosially meaningfull action, by using the semiotic approach.

The performances structure, medium of performances, as well as expressions of the performers of Sandhur can be observed by the reflection which attached to the marking pattern. Symbolic symptoms which systematically unraveled in the dynamics of the performances reveal the substance of the change of village culture caused by the process of urbanization, there is a change of living arrangements in accordance with the true nature and the laws of space and time changes.
\end{abstract}

Keywords: Sandhur, the agraris society, performance, tradition

\begin{abstract}
ABSTRAK
Pertunjukan Sandhur merefleksikan perubahan masyarakat agraris menuju budaya urban. Dalam Teks pertunjukan Sandhur terdapat kode hermeneutik, kode proairetik/tindakan naratif dasar, kode semantik, kode kultural, dan kode simbolik. Teks pertunjukan dapat dimaknai sebagai tanda dan simbol meresapnya budaya urban dalam kehidupan masyarakat Tuban. Hubungan manusia, Tuhan, alam, dan kebudayaan melekat pada struktur pertunjukan Sandhur. Kehidupan manusia menjadi bagian dari siklus kosmis yang utuh.

Untuk membaca, mendeskripsikan pertunjukan Sandhur digunakan pendekatan kualitatif, peneliti menjadi instrumen utama. Untuk memotret fenomena alamiah pertunjukan mengacu pada model etnografi. Untuk memahami teks pertunjukan Sandhur peneliti mempertajam analisis interpretatif terhadap socially meaningfull action digunakan pendekatan semiotik.

Struktur pertunjukan, medium pertunjukan, serta ekspresi pelaku pertunjukan Sandhur dapat diamati melalui refleksi simbolis yang melekat pada pola penandaan. Gejala simbolik yang terurai secara sistematik dalam dinamika pertunjukan mengungkapkan substansi perubahan budaya desa yang disebabkan oleh proses urbanisasi. Perubahan tatanan hidup sesuai dengan kodrat alamiah dan hukum perubahan ruang dan waktu.
\end{abstract}

Kata kunci: Sandhur, masyarakat agraris, pertunjukan, tradisi 


\section{PENDAHULUAN}

Istilah sandhur dalam penuturan masyarakat dimaknai sebagai bentuk pertunjukan untuk menghibur diri dan menghibur masyarakat. Dalam teks pertunjukannya dituturkan, "lare angon sesandhuran kangge nglipur ati para sedulur". Sandhur adalah tembung garba ${ }^{1}$ dari sandhing luhur, artinya berdampingan dengan leluhur. Dalam penuturan masyarakatnya sandhur juga diartikan sandhangan dhuwur, menyiratkan makna keluhuran. Kata dhuwur dan luhur berkaitan erat dengan leluhur yang dimuliakan. Pertunjukan sandhur merupakan aspirasi spiritual menjunjung tinggi leluhur yang berjasa "labuh labet babat alas dadi desa sing reja dadi dukuh sing makmur". Sandhur juga diartikan sebagai "beksan ngedhur" artinya menari semalam suntuk.

Pertunjukan sandhur menyajikan permainan dramatik yang menampilkan empat tokoh utama yaitu Balong, Petak, Tansil, dan Cawik. Secara kontekstual sandhur memiliki pertalian erat dengan pedhayangan, yaitu tradisi penghormatan leluhur desa--ritual nyekar di tempat yang diyakini dhanyang bersemayam--biasanya pertunjukan sandhur dilakukan pada beberapa pedhanyangan secara berurutan, pentas di tanah lapang, maupun pelataran rumah.

Tradisi pertunjukan sandhur dalam masyarakat petani daerah Tuban disajikan sebagai aktivitas ritual, mencerminkan peralihan budaya dan kesenjangan terhadap modernitas. Sandhur memberikan gambaran reflektif tentang rasionalitas, fakta sosial budaya terkait dengan sistem nilai kehidupan masyarakat (Hauser, 1982:95-98). Dalam tatanan sosial masyarakat petani, marginalitas, dan egalitarian memunculkan spontanitas, improvisasi, dan permainan terkait dengan religiusitas (tindakan magis, kamuflase, dan penyelesaian simbolis). Tradisi pertunjukan ritual menjadi pusat integrasi sosial masyarakat diungkapkan Huizinga sebagai dunia religius, spontan, asli, terlepas dari hukum empirik dan rasionalitas (1990: xx).

Dalam pertunjukan disajikan cerita kehidupan masyarakat agraris. Sandhur mengungkap kebijakan ekologi pertanian, perburuan, perdagangan, dan budaya urban yang ditengarai tumbuhnya peluang mencari pekerjaan di kota ${ }^{2}$. Permainan disajikan dengan berbagai atraksi ritual dan magis disertai cerita sebagai bentuk hiburan, dan katarsis. Dipaparkan oleh Huizinga bahwa permainan merupakan upaya untuk memuaskan hasrat hiburan, pembebasan diri dari tekanan, beban hidup, yang juga dipahami sebagai pembebasan kelebihan daya hidup (1990:26).

Sandhur menjadi citra tentang hajat hidup dan cita rasa yang dihayati oleh masyarakat. Nilai perubahan sosial budaya masyarakat dituturkan dalam permainan dramatis sandhur menggambarkan situasi sosial kemasyarakatan agraris menuju budaya industri dan menggambarkan peralihan tatanan hidup masyarakat pedesaan menuju budaya kota.

Permainan dramatis ditampilkan lewat garap medium gerak, vokal, permainan musik, citra busana, maupun penokohanyang merupakan citra estetika masyarakat petani. Model estetika ini menjadi bagian penting untuk menjaga kesadaran refleksi, fakta penipuan diri, hidup dengan tetapmengacu pada kebenaran hidup, dan mendialogkan langsung keberadaan manusia, dari masalah dan tugas kehidupan nyata. Arnold Hauser menyatakan,

"it is part of art's essence to keep to consciousness of reflection, the fact of self deception, alive by constantly alluding to reference to reflected truth. [...] the most important works are often direct discussion of human existence, of the problem and tasks of real life (1978:317).

\section{METODE}

Penelitian terhadap sandhur dilakukan dengan menggunakan pendekatan kuali- 
tatif, peneliti menjadi instrumen utama dalam penelitian. Pendekatan dilakukan untuk memotret fenomena alamiah pertunjukan Sandhur Tuban. Deskripsi mengacu model etnografi; untuk memahami teks pertunjukan sandhur peneliti mempertajam analisis interpretatif terhadap socially meaningfull action. Dalam memotret dan membaca teks pertunjukan penulis melakukan pengamatan langsung dan terperinci terhadap masyarakat penutur tradisi pertunjukan sandhur sebagai perilaku sosial dan perilaku estetik (Turner 1986: 139).

Pendeskripsian dan penafsiran terhadap makna yang terkandung dalam pertunjukan, dilakukan dengan pemaparan penggambaran naturalistik model berdasarkan tuturan emik pertunjukan sandhur, lingkungan masyarakat, dan kebulatan kosmisnya. Interpretasi terhadap fokus pertunjukan dilakukan dengan mendeskripsikan secara analitis tanda, kode, dan simbol untuk mencapai kedalaman nilai insani dan humani pertunjukan sandhur. Gambaran konkrit refleksi budaya urban masyarakat agraris terdapat pada paparan analitis interpretatif terhadap pola ekspresi simbolik pertunjukan sandhur dalam lingkungan masyarakat.

\section{HASIL DAN PEMBAHASAN}

\section{Masyarakat Pedesaan di Kabupaten Tuban}

Tuban terbagi menjadi dua wilayah geografis yaitu wilayah pantai, wilayah dataran yang terdiri dari lembah datar, dan pegunungan kapur. Masyarakat pantai hidup sebagai nelayan, pedagang, dan beberapa di antaranya bekerja di bidang transportasi. Wilayah pedesaan yang membentang luas dengan hutan, bukit kapur, hamparan sawah, dan ladang menuntun masyarakat bercocok tanam menggarap sawah, ladang, dan kebun disekitar rumah.

Pada musim hujan mereka menanam padi di sawah, pada beberapa lahan yang tidak mendapatkan air secara baik, dita- nami jagung, kacang tanah, atau sayursayuran. Di wilayah bukit kapur biasanya ditanami buah-buahan, mangga, srikaya, pisang, pepaya, maupun palawija yang dapat memberikan nilai tambah untuk memenuhi kebutuhan hidup mereka.

Pada lahan kering tegalan terdapat pohon siwalan/enau, di sela-sela pohon ini ditanami kacang tanah, jagung, dan singkong. Pohon siwalan/enau menghasilkan gula merah, legen, dan tuak ${ }^{3}$. Pohon ini menghasilkan gula, legen, dan tuak merupakan produk unggulan yang dibanggakan oleh sebagian masyarakat. Gula, legen, dan tuak mendapatkan tempat khusus karena menjadi salah satu penghasilan pokok masyarakat setempat.

Tuak dan legen dipasarkan di pinggiran jalan mulai pagi hari sampai tengah malam. Para pria dewasa minum tuak sebelum dan sesudah bekerja. Minuman tradisional ini dinikmati oleh sebagian besar masyarakat yang memposisikan legen tuak sebagai aset ekonomi dalam kehidupan masyarakat Tuban.

Masyarakat petani pedesaan masih memiliki gaya dan pandangan hidup bersahaja. Sikap gigih dalam bekerja keras selalu disertai sikap pasrah dan bersyukur terhadap hasil yang dicapainya. Sikap dan pandangan hidupnya dipandu oleh berbagai rujukan religi, baik yang bersumber pada agama resmi maupun ajaran kebatinan Jawa. Ajaran kebatinan Jawa Sumarah dan 'Islam Abangan' memiliki pengaruh kuat. Pada dinding rumah mereka dipajang potret tokoh spiritual mereka-Ki Ageng Suryomataram, Sunan Kalijaga, dan Walisanga-hal ini merefleksikan sikap hormat dan kedalaman hubungan batin mereka dengan tokoh-tokoh ini.

Di rumah dipajang kata-kata semboyan, bagan skematis tentang ajaran kebatinan yang dipahami sebagai penuntun perilaku bermasyarakat. Religiusitas menuntun masyarakat selalu menggunakan pétung ${ }^{4}$ dalam 
untuk melakukan kegiatan-kegiatan penting. Pétung terhadap semua hal yang dilakukan, menuntun masyarakat untuk selalu melihat fenomena alam dan mencari hubungan-hubungan antara dirinya dan alam. Melalui sistem pétung terbangun keserempakan aktivitas sosial budaya mulai dari bertanam padi, jual beli ternak, hajat perkawinan, khitanan, mendirikan rumah, pindah tempat tinggal, dan sedhekah bumi. Pétung masih berlaku dalam kehidupan masyarakat terintegrasi secara utuh dalam siklus kosmis (Geertz, 1981:38-40).

Sebagian besar masyarakat pedesaan memiliki orientasi berpikir yang setara tentang aktivitas sosial budaya mereka. Masyarakat Semanding, Palang, Kering, Randhu Pokak, Bektiharja ${ }^{5}$ (Joko Susilo, 2011:7-8) juga beberapa wilayah pedesaan lainnya merupakan masyarakat yang relatif patuh pada tradisi pétung. Pétung merupakan sistem rasional yang secara kontekstual menyatakan hubungan manusia, lingkungan alam, dan aktivitas sosial budaya.

Desa-desa tersebut terletak di pinggiran kota Tuban radius 6-20 km merupakan zona yang memiliki peluang besar terjadinya migrasi dari desa ke kota ${ }^{6}$. Banyak warga desa bekerja pulang balik dari desa ke kota, bekerja dalam jangka waktu yang lama di kota sebagai pelayan, pekerja bangunan, penarik becak, sopir, atau berdagang (Poerwanto, 2000:94-96). Ini merupakan peluang terjadinya perubahan pada berbagai aspek kehidupan sosial dan budaya masyarakat pedesaan.

Jalan Daendels yang membentang dari Anyer sampai Panarukan melintasi kotaTuban memiliki pengaruh signifikan, antara lain didirikannya pasar, gudang, pertokoan, terminal berbagai kendaraan, rumah makan, dan warung di sepanjang perlintasan jalan. Hal ini membuka ruang perubahan bagi tata perkotaan Tuban, perubahan sosial masyarakat (peluang kerja, berbagai status sosial yang muncul karena jenis pekerjaan baru, mobilitas sosial, dan percepatan sirkulasi uang, barang, dan jasa), sehingga menumbuhkan budaya urban. Terjadi peralihan mendasar dari struktur masyarakat petani tradisional menuju masyarakat perkotaan yang bergerak menuju tradisi baru (Sjafri Sairin, 2002:170-173).

Perubahan sosial mengubah berbagai tatanan masyarakat sebagaimana dituturkan oleh Agus Salim bahwa perubahan karena pola hubungan kerja, terjadi dari perkembangan masyarakat agraris ke bentuk masyarakat industri. Dinamika kebudayaan masyarakat lokal, terjadi akibat modernisasi gaya hidup, dan terbentuknya masyarakat komersil dalam kemasan tradisi lokal (2002: 158).

Telah terjadi adanya proses peralihan mendasar pada berbagai aspek kebudayaan sehingga menyentuh tradisi yang mendasari kehidupan masyarakat di pedesaan. Desa sebagai suatu sistem, menuntun respons masyarakat untuk mengadopsi berbagai nilai yang diserapnya dari tata kehidupan kota (Edward Shils, 1983:258-260). Refleksi dari berbagai bentuk peralihan melekat pada tradisi pertunjukan dalam tatanan kehidupan masyarakat pedesaan. Perubahan ini diakibatkan perkembangan atau pertumbuhan kota-kota di Indonesia. Perkembangan kota sebagai pertumbuhan ekonomi suatu wilayah dikaitkan karena ada perubahan bentuk kekuasaan administratif atau birokrasi, atau perkembangan sektor riil (Agus Salim, 2002: 157).

\section{Pertunjukan Sandhur}

Pertunjukan sandhur dimulai dari memilih dan menentukan pemain Balong, Petak, Tansil, dan Cawik. Pemilihan pemain diambil dari kelompok bocah angon 'anak gembala' yang belum khitan. Bocah angon yang belum khitan masih suci menjadi media merasuknya roh leluhur, malaekat maupun bidadari. Pemeran Balong, Petak, Tansil, dan Cawik harus menjalani tirakat 
yaitu tidak boleh keluar rumah selama tujuh hari, dan pada penghujung tirakat para pemeran menjalani puasa ngebleng ${ }^{7}$.

Selanjutnya dilakukan ritual nyetri sandhur yaitu berziarah ke tempat-tempat keramat (makam leluhur, pepundhen). Juru kunci menuntun peziarahan pemain sandhur yaitu Panjak hore, Balong, Petak, Cawik, dan Tansil. Semua peralatan disertakan dalam kegiatan nyetri yang meliputi: busana sandhur, ebeg (jaran kepang), tali (kentheng), kendang, dan gong bumbung. Pelaku pertunjukan beranggapan bahwa peralatan yang dibawa nyetri mendapatkan kekuatan sehingga pertunjukan berjalan dengan baik. Kegiatan dilakukan selama tujuh hari dari makam satu ke makam lainnya (Damami, 2002: 59-60).

\section{Awal Pertunjukan}

Sebelum pertunjukan sandhur dimulai, juru paes sandhur, tukang sajen, mempersiapkan sesaji yang terdiri dari: tumpeng beserta lauk pauk, cowek, uleg-uleg, daun keluwih, dupa, merang, ketupat, lepet, dan berbagai jenis jajanan yang merefleksikan citra dan cita rasa kemakmuran yang diinginkan masyarakat. Pertunjukan diawali dengan tahapan gambuh kalangan. Pada tahapan ini panjak hore menyajikan lagu-lagu yang memberikan isyarat penonton untuk berdatangan. Para pemain sudah siap, panjak hore duduk mengelilingi gagar mayang yang dipancangkan di tengah arena. Syair yang dilantunkan merupakan penggambaran proses pembuatan kalangan (arena).

Kalangan dibuat pada siang hari di atas tanah berukuran sekitar $6 \times 6 \mathrm{~m}$. Pada tiap sudut dipancangkan tiang (pathok) yang dihubungkan dengan tali sehingga membentuk sebuah arena. Kalangan ditandai hiasan janur kuning, kupat, lepet pada sisi kễnthễng/tali pembatas dengan disertai lantunan mantra,

"Bismillahhirrohma nirohim/lale lo lahrase lolah/ lolalela lolelala lo la lelalolalo lelala le- laloyakelolalalolalelalo/yakelolaraselollah/kembang ketupukkanca Sandhur pada mlumpukl yak elolahraselolah/ lolelelalolelalalo lalela lo lalolela/lalelalo yak elolala lolalelalo nyak elolara selollah".

Lagu pertama dibuka dengan bacaan Basmallah, kemudian dilanjutkan dengan melantunkan syair yang menyajikan pencandraan kegiatan persiapan pentas antara lain, kembang otok, kanca sandhur, masang pathok (bunga otok, teman sandhur memasang tiang), kembang johar, kanca sandhur, masang blabar (bunga johar, teman sandhur, memasang tali), kembang plasa, kanca san-dhur, nggelar klasa (bunga plasa, teman sandhur, menggelar tikar), kembang gedhang, kanca sandhur, masang kendang (bunga pisang, teman sandhur memasang kendhang). Setelah kalangan selesai dilanjutkan adegan gambuh pedhanyangan, berisi tanduk permohonan ijin kepada leluhur, "kembang trenienjaluk idhi danyang kene/yakelolahraselolah/lolelela lolelala lolalelalo lalolela/lalelalo yake lolallolalelalo/yak elolaraselollah. Lagu ini dinyanyikan berulang-ulang, syair bait pertama diganti sesuai dengan kebutuhan; empat baris selanjutnya tetap.

Setelah memasuki kalangan dalam keadaan lugas--tanpa kostum dan rias-disajikan adegan bendrong lugasan. Proses diawali panjak hore melantunkan lagu sorak hore yang muncul dari belakang kerumunan penonton, prosesi terdiri dari tukang oncor, diikuti tukang umpet, sajen, Balong, Tangsil, Pethak, Cawik, tukang kandut dan paling belakang tukang oncor. Prosesi menari mengelilingi gagar mayang tiga tali untuk menuju tempat paras/rias. Adegan ini disebut bendrong lugasan karena belum memakai busana pentas. Selanjutnya adegan gambuh paras yaitu proses pemain merias wajah dan berbusana lengkap. Pemain memasuki dunia sakral dan magis dalam pertunjukan sandhur. Peralihan adegan ditandai munculnya pemeran Balong, Petak, Tangsil, Cawik yang mulai mengenakan kostum, juru paes (perias wajah) mulai me- 
matut pakaian pemain dan kemudian merias wajah mereka.

Selesai paras, pemain sandhur diarak kembali memasuki kalangan, dengan urutan gambuh lugasan yaitu terdiri dari paling depan tukang oncor diikuti mulai dari Tangsil, Pethak, Cawik dan Balong serta tukang kandut, tukang umpet, dan paling belakang tukang oncor. Prosesi menari mengelilingi panjak hore tiga putaran sampai di sisi timur. Pemain sandhur berjongkok menghadap panjak hore dan gagar mayang. Adegan ini disebut gambuh Sandhur, para pemain berbusana lengkap untuk memulai pertunjukan, tetapi masih berkerudung.

\section{Bagian Inti Pertunjukan}

Pertunjukan diawali dengan tanduk, yaitu resitasi atau pembacaan mantra memasuki inti pertunjukan ritual sandhur. Setiap dua bunyi vokal sebelum akhir kalimat dibaca dengan suara memanjang. Setiap akhir pembacaan kalimat-kalimat mantra disahuti dengan kata inggih--tanda mengiyakan/dikabulkan--secara serentak oleh pemain sandhur dan penonton. Tanduk sandhur berisi paparan tujuan pertunjukan sandhur, teks awal tanduk sandhur dikutip sebagai berikut:

"Kulo badhe mratelakaken lare angon se sandhuran, yen rino gumelar ing kebon, yen sore jejogetan ing latar. Dherek-dherek jejer pinarak lenggah ing mriki sedoyo, dherek kulo sakjawine ketheng lan salebete kentheng, mboten kulo wastani setunggal-setunggalipun".

[Saya akan menceritakan anak gembala bermain Sandhur, bila siang bekerja di ladang, bila diwaktu sore menari-nari di halaman. Saudara-saudara berkumpul duduk di sini, saudara saya yang diluar dan di dalam arena semua tidak saya tunjuk satu persatu].

Setelah tanduk pertunjukan sandhur diawali dengan adegan golek gawean, inti pertunjukan diawali perjalanan hidup Pethak mencari pekerjaan kepada Wak Germo dan Balong. Pethak diterima Balong membantu menggarap ladang. Balong tidak punya modal maka Pethak disuruh menggadaikan bedhil (senapan) ke Wak Germo. Uang gadai sebagian untuk nanggap sindhir (tayub) dan sebagian untuk 'babat alas' membuka ladang. Pethak menjemput sindhir di rumah Wak Germo. Dalam adegan sindhiran (tayub), sindhir diperankan oleh Cawik, sedangkan Pethak, Tangsil, dan Balong menjadi pengibing.

Adegan bancik endhog, para pemain sandhur berurutan menginjakkan kaki pada endhog (telur) secara bergantian. Bancik endhog itu adalah berdiri di atas telur sebagai simbol dunia. Adegan berikutnya adegan bancik kendhi, pemain sandhur secara berurutan naik di atas kendhi secara bergantian. Bancik kendhi berarti berdiri di atas kendhi berisi air jernih sebagai simbol manusia harus berpikiran jernih dan kendhi tidak boleh kosong, kalau kendhi kosong maka dimakan Bathara Kala.

Adegan babat alas menjadi lanjutan dari adegan bancik kendhi. Pethak disuruh Balong menjual bedhil. Hasil penjualan bedhil digunakan untuk nanggap sindhir dan sebagian untuk babat alas. Adegan berikutnya berupa lawakan yang menyajikan adegan waker dan mantri alas. Adegan berupa lawakan yang menceritakan mantri alas dan seorang waker/penjaga hutan.

Setelah adegan babat alas dilanjutkan adegan mengolah tanah/lahan pertanian. Pertama Ngrakal, menceritakan pekerjaan seorang petani membajak ladang dan sawah, icir (menanam) jagung. Adegan ini dilengkapi adegan nyai-nyaian sebagai penyela. Adegan sambang tegal menceritakan petani memeriksa tanaman di ladang. Sambang tegal ini biasa dilakukan petani desa untuk memeriksa tanaman dan kadangkadang sambang tegal dilakukan malam hari untuk menjaga tanaman atau hewan ternak dari pencuri.

Adegan selanjutnya, adegan lucu yang menceritakan Wak Kaji mencuri babi hutan, yang sebelumnya sudah dicuri oleh Cina 
Dengklang. Adegan ini merupakan sindiran bagi seseorang yang berbuat tanpa melihat kepatutan perbuatan dengan kedudukan yang disandang. Setelah lawakan disajikan adegan Undhoh-undhoh menceritakan petani memanen tanaman di ladang.

Adegan berikutnya berupa gambaran proses sosial dalam membangun rumah tangga. Adegan diawali adegan bancik dhengkul dan bancikpundhak. Bancik dhengkul menampilkan pemain sandhur bergantian naik di atas lutut tukang tanduk, sebagai simbol manusia setengah dewasa, punya pengalaman luas. Bancik dhengkul berarti meninggalkan bumi, simbol pendekatan diri kepada Tuhan. Bancik Pundhak, pemain sandhur berdiri di atas pundhak panjak hore. Adegan merupakan simbolisasi dari pencapaian spiritualitas tertinggi, sebagai manusia sempurna.

Adegan yang mengawali menggambarkan masalah sosial dalam kehidupan seharihari terkait dengan mencapai martabat dan kemuliaan hidup, antara lain Madeg Ratan berkaitan erat dengan pencarian tempat untuk dijadikan jalan. Pethak Minggata degan ini menceritakan tentang keinginan Pethak untuk menikah, tetapi tidak diijinkan oleh orang tuanya.

Manten-mantenan, merupakan kelanjutan dari adegan Pethak Minggat menceritakan pernikahan Pethak dengan Cawik. Besan-besanan, adegan ini menceritakan kisah tentang Cawik yang seolah digoda oleh Balong, yang menyebabkan kemarahan Pethak. Kemarahan Pethak terhadap Cawik menyebabkan retaknya pernikahan mereka, akhirnya mereka rujuk kembali. Adegan Cawik Mbobot, menceritakan Cawik mengandung buah perkawinannya dengan Pethak. Nyolong klopo menceritakan saat hamil, Cawik ingin dibelikan rujak, tetapi Pethak tidak punya uang. Pethak mencuri kelapa untuk membeli rujak. Bandan menceritakan Pethak tertangkap pada saat mencuri.

\section{Bagian Akhir Pertunjukan}

Bagian akhir pertunjukan berupa $\mathrm{Ka}-$ longkingan, yaitu saat pemain menari dengan mengelilingi gagar mayang. Ketika salah satu anak Sandhur tidak sadarkan diri, kemudian juru kunci melepas seluruh asesoris busana Sandhur. Anak tersebut dibopong (digendong) mengelilingi gagar mayang dan diikuti para penari. Suasana magis mulai terasa, anak yang dibopong diikat erat-erat dimasukkan ke kolong meja yang ditutup kain sehingga tidak terlihat, dalam sekejap anak tersebut telah bebas dari ikatan tali dan keluar dari kolong meja. Pemain tampil dalam keadaan tidak sadarkan diri. Selanjutnya anak tersebut dibawa ke gagar mayang di mana terdapat tali yang menjulang tinggi ke atas yang tersambung dengan tali melintang yang tersambungkan dengan dua batang bambu. Suasana semakin mencekam karena anak yang dalam keadaan tidak sadar tadi, tangannya disentuhkan pada tali. Pemain menari di atas seutas tali direntangkan di atas pancang bambu sambil mengambil kupat lepet yang digantungkan pada tali. $\mathrm{Ku}-$ pat lepet dilempar ke penonton, penonton yang dapat menangkap kupat lepet percaya mendapatkan keberuntungan.

Pada saat yang sama, panjak hore melantunkan lagu kalongking pembuka. Pandangan penonton menatap ke atas di mana anak tersebut menari di atas tali. Adegan kalongking atau bandulan ini tidak boleh menggunakan alat penerang lampu apapun termasuk memotret, karena apabila dilakukan akan mencelakakan penari. Selain ada yang menyanyi, anak-anak ada yang berteriak "mudhun cung wis padhang cung (turun nak sudah pagi nak)". Bila kalongan akan turun atau sudah turun setengah tali, ada yang berteriak "munggah cung-munggah cung iseh bengi cung (naik nak, naik nak masih malam nak)". 


\section{Refleksi Simbolis}

Wilayah budaya pantai (Tuban, Lamongan, Bojonegara) yang agraris menumbuhkembangkan tradisi sandhur, suatu ekspresi drama, tari, dan nyanyi. Estetika sandhur merupakan gugus simbolik budaya agraris tradisional menyongsong budaya urban, merefleksikan perubahan kosmis, manusia sebagai bagian dari masyarakat dalam merespons perubahan alam. Hal ini dapat diamati pada struktur sajian sandhur maupun tokoh yang dimainkan di dalamnya, yaitu Pethak, Tangsil, Balong, dan Cawik.

Pada bagian lebih mendalam dapat diamati penutup cerita sebagai refleksi simbolis nilai-nilai kehidupan yang dihayati oleh masyarakat. Terdapat tiga gugus simbol yang tertuang pada perilaku tokoh, adegan, dan narasinya. Sandhur dalam konteks seni menjadi penting dalam kehidupan masyarakat dan budaya adati. Masyarakat dalam peradaban yang dihayatinya, menciptakan kode, tanda, dan simbol untuk menyatakan sisi kehidupan yang pelik dalam membangun harkat dan martabat kemanusiaannya. Terdapat adanya hubungan yang signifikan antara manusia, lingkungan, agama, dan kebudayaan yang totalitasnya terungkap dalam pertunjukan (Sobur, 2003: 178-179).

Sebagai tanda dan simbol sandhur dipenuhi kode-kode dalam ungkapan estetiknya. Untuk melihat refleksi simbolis digunakan pemikiran Roland Barthes yang mengelompokkan kode-kode menjadi lima kisi-kisi, yakni kode hermeneutik, kode semantik, kode simbolik, kode narasi proairetik, dan kode kultural atau kode kebudayaan (Kurniawan, 2001:69-71).

Kode hermeneutik mengandung tekateki/enigma yang dapat dibedakan, diduga, diformulasikan, dipertahankan, dan diungkap sebagai bentuk kebenaran. Kode Semantik, yaitu kode yang mengandung konotasi pada level penanda. Misalnya konotasi feminitas, maskulinitas. Kode
Semantik adalah tanda-tanda yang ditata sehingga memberikan konotasi maskulin, feminin, kebangsaan, kesukuan, dan, loyalitas. Kode Simbolik, yaitu kode yang berkaitan dengan psikoanalisis, antitesis, kemenduaan, pertentangan dua unsur, skizofrenia. Kode narasi proairetik yaitu kode yang mengandung cerita, urutan, narasi atau antinarasi. Kode budaya atau kultural, yaitu suara-suara yang bersifat kolektif, anonim, bawah sadar, mitos, kebijaksanaan, sistem pengetahuan, sejarah, moral, psikologi, sastra, seni, dan legenda (Yasraf A. Piliang, 2003:223-226).

Dinamika simbolis dalam struktur pertunjukan sandhur dapat dibagi menjadi 3 tiga struktur dasar. Pra pertunjukan dalam struktur dramatik sandhur merupakan oreintasi ruang kosmis yang dituntun oleh mitos, memuat orientasi ruang personal sebagai jagad cilik, serta kemurnian alam dan daya imanen yang dipersepsikan sebagai daya ilahiah. Penyatuan antara jagad cilik dan jagad gedhe yang imanen diwujudkan dalam nyetri, pedhanyangan. Ini menjadi gambaran natural kehidupan pertunjukan yang berakar pada hubungan manusia yang insani dan humani.

Dalam struktur awal dapat dilihat hubungan alamiah antara pelaku sandhur, masyarakat, dan lingkungan alam serta ruang imanennya. Nyetri menyapa ruang kosmis yang suci (sendhang, pundhen, dhanyang) untuk mendapatkan sentuhan dayadaya imanen, kekuatan ilahiah. Sendhang, pundhen, dhanyang merupakan kode narasi. Mitos sendhang, pundhen, dhanyang secara historis dikaitkan dengan Bapa Adam Ibu Hawa, Nabi, dan Wali (dinarasikan dalam hubungan keluarga, guru murid, persekutuan) sehingga menjadi kerangka mistik dan ideologi kultural.

Sandhur nyetri dalam konteks penuturan adati merupakan perilaku religi yang membangun hubungan transendental antara tokoh mitologi, legenda pundhen, sen- 
dhang, dan para pelaku pertunjukan sandhur sebagai anak putu dengan melakukan kegiatan nyekar, berdoa, menyemayamkan peralatan pentas di sendhang dan pundhen. Hal ini merupakan bentuk pemuliaan, permohonan berkah, serta merasuknya imanensi kudus dalam dunia pertunjukan.

Nyetri sebagai ekspresi pertunjukan memberikan ruang orientasi kejiwaan bagi pemeran Pethak, Tangsil, Cawik, dan Balong pada tataran ekstase. Pencapaian trance sebagai bentuk ekstase dalam konvensi tradisi sandhur didekati melalui nyetri. Pethak, Tangsil, Cawik, dan Balong diperankan oleh jejaka kecil (jaka cilik) yang belum khitan diyakini masih suci sebagai mediator antara jagad alus dan jagad kasar.

Kesucian empat pemeran --Pethak, Tangsil, Cawik, dan Balong-- dalam sandhur merupakan ruang 'trans' sebagai ambang liminal antara daya ilahiah dan dunia nyata. Peralihan padhang peteng, hitam putih, dalam konteks pertunjukan sandhur, merupakan fenomena virtualitas. Ruang virtual dibangun oleh kesucian empat tokoh yang diperankan oleh anak laki-laki berstatus "bocah angon". Gambuh kalangan, bendrong lugasan, gambuh paras, dan gambuh sesandhuran memiliki struktur yang memberikan gambaran prosedur sistemik yang dilalui sebagai tata laku pertunjukan.

Kode narasi proairetik juga terdapat pada adegan Tanduk Sandhur, Golek gaweyan, Babat alas, Waker, Mantri alas, Ngrakal, Nyai-nyaian, Icir, Sambang tegal, Kaji-kajian dan Cina dhengklang, Undoh-ondoh, Madeg Ratan, Pethak minggat, Manten-mantenan, Besan-besanan, Cawik mbobot, Nyolong klapa, dan Bandan. Berbagai cerita ini menyajikan narasi realis tentang fakta sosial masyarakat pedesaan, keluarga, dan dinamika berumah tangga. Narasi merupakan pencerminan siklus hidup runtut sesuai dengan fakta sosial danfakta psikologis masyarakat pedesaan.

Narasi proairetik mencerminkan kehidupan keluarga yang insani dan humanis, yaitu bicara tentang rumah, ladang, dan kehidupan sosial yang natural. Nilai-nilai yang diungkapkan merupakan nilai yang membumi. Narasi proairetik menunjukkan kehidupan yang terintegrasi secara utuh dengan siklus alam. Manusia merupakan bagian yang tak terpisahkan dari rangkaian siklus ruang dan waktu pada alam pedesaan. Ini sangat berbeda pada kode simbolik yang terungkap pada adegan Waker dan Mantri alas, Kaji-kajian dan Cina dhengklang.

Lawakan Waker dan Mantri alas, Kajikajian dan Cina dhengklang, merupakan fakta budaya urban yang terungkap melalui Sandhur. Hubungan sosial Waker dan Mantri alas mencerminkan atasan dan bawahan. Hal itu, pada tatanan sosial masyarakat petani merupakan bentuk hubungan yang dipengaruhi oleh tatanan birokrasi, institusi resmi berbeda dengan lembaga budaya adati. Perbedaan pangkat (dikotomi; paradoks), terdapat komunikasi sosial linier, menuntut loyalitas dan dedikasi. Bentuk hubungan sosial formal dalam masyarakat pedesaan umumnya sangat tipis.

Adegan kaji-kajian dan cina dhengklang, menyimpan kode semantik untuk membicarakan masalah kesukuan dan agama. Homogenitas masyarakat pedesaan agraris sangat peka terhadap hadirnya sesuatu yang berbeda dengan fakta sosial, religi, ekonomi. Kaji-kajian (haji) merupakan status sosio religi yang tinggi dalam kehidupan masyarakat pedesaan. Begitu pula Cina yang kemudian menjadi refleksi dari kemapanan sosial ekonomi.

Lawakan yang tersaji dalam adeganadegan merupakan sesuatu yang terpendam sangat dalam pada memori serta menjadi nyata dalam pertunjukan. Figur kaji/haji dan Cina merupakan simbol kemapanan status sosial ekonomi. Citra kota, kemapanan ekonomi, yang tampil dalam adegan merupakan gejala merasuknya budaya kota ke dalam kehidupan masyarakat pedesaaan. 
Merasuknya budaya kota ke desa atau sebaliknya menjadi tema signifikan dalam menyampaikan beberapa perubahan masyarakat lingkungan sosial dan budaya. Lawakan sebagai katarsis dan menyegarkan memberikan gambaran tentang perubahan yang muncul dalam masyarakat. Indikasi ekspresi dalam pertunjukan menunjukan bahwagejala urban memiliki pengaruh besar terhadap semua sisi kehidupan petani dipedesaan. Hal ini sepadan dengan ungkapan Turner bahwa pertunjukan dramatis maupun ritual dalam konteks pertunjukan menjadi refleksi fakta sosial budaya masyarakatnya (1986:10-11).

Bancik endhog, bancik kendhi, bancik dhengkul, dan bancik pundhak, adalah sesuatu yang ganjil dalam pertunjukan karena adegan ini sama sekali tidak ada hubungan tematik dengan narasi dan penutup cerita. Ini merupakan simbol budaya filsafati terkait dengan siklus kehidupn. Bancik endhog, kelahiran, bancik kendhi tanda kehidupan, bancik dhengkul kode laku/perjalanan hidup/ dan bancik pundhak identik dengan pencerahan tertinggi sebagai kedewasaan manusia penuh tanggungjawab. Kode semantik memberikan citra khas tanda alamiah terkait dengan tradisi adati.

Struktur pertunjukan sandhur mengingatkan kita pada diagram Schechner The Fan And The Web. Pertunjukan memiliki pola sistemik dalam struktur tatanan linier dan hirarkies seperti jeruji kipas. Setiap jeruji merupakan kerangka hubungan antara pertunjukan dengan aspek genetik pertunjukan yang menjadi penanda hubungan antara ekspresi pertunjukan dan ritual, proses penciptaan seni, permainan, pertunjukan kehidupan sehari-hari, olah raga, entertainment, pemecahan masalah kehidupan maupun erupsi, shamanisme, ritus dan perayaan yang melekat dalam fakta sosial budaya masyarakat (Schechner,1977:xi-xiv).

Terdapat hubungan dari ritual ke pertunjukan di mana genetika pertunjukan membangun ekspresi unik, sebagaimana kehidupan nyata pelaku pertunjukan memberi ruh pertunjukan sandhur. Ekspresi tersebut tergambarkan dalam struktur tanda, narasi, kode-kode, dan kesatuan simbolnya.

\section{Kalongking: Sufisme dalam Tradisi Kerakyatan}

Adegan paling akhir, kalongking merupakan adegan trance yang ditempatkan pada ruang dan waktu penghujung pertunjukan. Pemeran kalongking menaiki tali yang direntangkan pada dua tiang pancang bambu. Pada ketinggian sama dengan pohon bambu, diterangi obor dari bawah; dimensi gelap terang, tampak dan tidak tampak, jelas dan samar, bumi langit, atas dan bawah. Adegan ini merupakan kode simbolik kehidupan. Dialog "mudhun cung wis padhang cung (turun nak sudah pagi nak)", dan sebaliknya, "Munggah cung-munggah

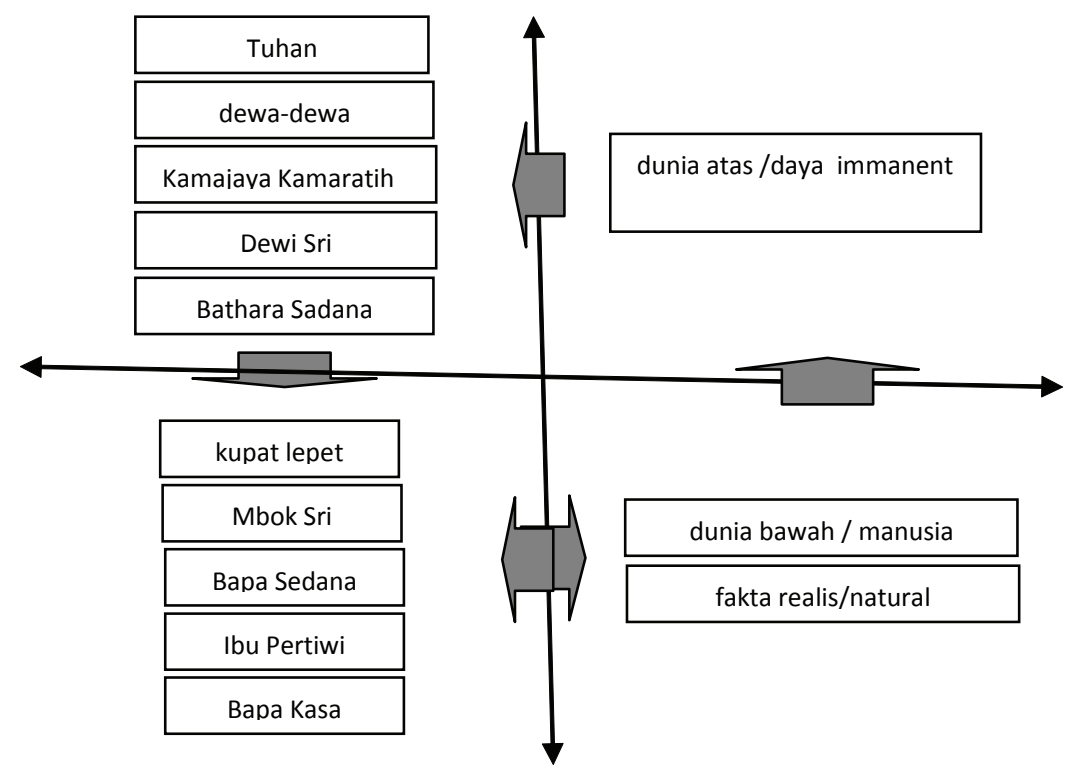

Bagan 1.Pola simbolik pertunjukan Sandhur dalam tata hubungan alami manusia dan Tuhan 
Tabel 1. Pola Kode Simbolik Kultural

\begin{tabular}{|c|c|c|c|}
\hline No. & Adegan & Misi/refleksi & Keterangan \\
\hline 1 & \multicolumn{3}{|c|}{ Nyetri Sandhur dan Gambuh } \\
\hline & $\begin{array}{l}\text { Nyetri Sandhur, Gambuh kalangan, Gambuh } \\
\text { pedhayangan, bendrong lugasan, Gambuh } \\
\text { paras, dan Gambuh Sesandhuran. }\end{array}$ & $\begin{array}{l}\text { Membangun hubungan } \\
\text { dengan daya Illahiah, } \\
\text { leluhur. }\end{array}$ & $\begin{array}{l}\text { Kode kulutral berkenaan de- } \\
\text { ngan religiusitas, spiritualitas, } \\
\text { Kode proairetik naratif. }\end{array}$ \\
\hline 2 & \multicolumn{3}{|c|}{ Pertunjukan Sandhur } \\
\hline & $\begin{array}{l}\text { Tanduk Sandhur, Golek gaweyan, Babat } \\
\text { alas, Waker Mantri alas, Ngrakal, Nyai- } \\
\text { nyaian, Icir, Sambang tegal, Kaji-kajian dan } \\
\text { Cina dhengklang, Undhoh-undhoh, Madeg } \\
\text { Ratan, Pethak minggat, Manten-mantenan, } \\
\text { Besan-besanan, Cawik mbobot, Nyolong } \\
\text { klapa, Bandan. }\end{array}$ & $\begin{array}{l}\text { Refleksi siklus hidup, ke- } \\
\text { bijakan ekologi. }\end{array}$ & $\begin{array}{l}\text { Kode naratif proairetik tentang } \\
\text { realitas kehidupan masyarakat } \\
\text { pedesaan yang agraris. }\end{array}$ \\
\hline 3 & $\begin{array}{l}\text { Bancik endhog, bancik kendhi, bancik dheng- } \\
\text { kul, bancik pundhak. }\end{array}$ & $\begin{array}{l}\text { Hirarkie refleksi tataran } \\
\text { hidup yang dicapai. }\end{array}$ & $\begin{array}{l}\text { Kode simbolik, hermeneutik, } \\
\text { semantik tentang tataran hi- } \\
\text { dup, ruang dan waktu terkait } \\
\text { dengan filsafat hidup. }\end{array}$ \\
\hline 4 & $\begin{array}{l}\text { Waker mantri alas, Kaji-kajian, Cina dheng- } \\
\text { klang }\end{array}$ & Lawakan. & Kode simbolik, semantik. \\
\hline 5 & Kalongking/Kalongan. & Refleksi makrifat/sufisme & $\begin{array}{l}\text { Kode simbolik, hermeneutik, } \\
\text { semantik tingkat pencerahan } \\
\text { budi }\end{array}$ \\
\hline 6 & $\begin{array}{l}\text { Penari memanjat tali yang dikaitkan pada } \\
\text { ujung bambuyang dipancangkan. }\end{array}$ & $\begin{array}{l}\text { Pencerahan melalui renung- } \\
\text { an suci. }\end{array}$ & $\begin{array}{l}\text { Kode simbolik kultural terkait } \\
\text { dengan kearifan lokal dan ke- } \\
\text { arifan hidup. }\end{array}$ \\
\hline
\end{tabular}

cung iseh bengi cung". Narasi simbolik tentang pencerahan yang dicapai terungkap pada kalimat, "mudhun cung wis padhang cung" memberikan gambaran konkrit tentang ketuntasan dalam mencari pencerahan hidup (Dillistone 2002: 61-62).

Pencapaian pencerahan tersebut sangat dekat dengan isbat" padhang kalingan peteng" atau sebaliknya "peteng kalingan padhang" [terang tertutup oleh kegelapan, atau kegelapan tertutup oleh cahaya terang]. Ruang tafsir yang dilontarkan merupakan dimensi ruang batin masyarakat dalam mencari pencerahan--melalui kedalaman ego untuk memahami--ruang sufi yang suci dan imanen (Geertz, 1981:416-417). Religi murni tumbuh dalam masyarakat yang terefleksikan pada adegan kalongking. Kupat lepet yang digantung pada rentangan tali pada ujung bambu kemudian pelemparan ketupat lepet pada penonton. Jelas bagian dari kode simbolik tentang pemberkatan, pencapaian kemuliaan, dan pencerahan. Kupat lepet dalam kehidupan masyarakat merupakan simbol kesuburan dan kemakmuran, ditandai penyatuan spiritualitas laki-laki dan perempuan. Bapa Angkasa Ibu Pertiwi, Mbok Sri Bapa Sedana merupakan deretan nama pada mistik Jawa mendekati dimensi daya imanen dan spiritualitas yang dihayati masyarakat. Pola kode simbolik kultural dapat dilihat pada Tabel 1.

\section{SIMPULAN}

Mengamati struktur pertunjukan, medium pertunjukan, serta ekspresi para pelaku pertunjukandapat diambil saripati refleksi simbolis yang tercerminkan melalui pola penandaan yang diungkap dalam bentuk kode-kode naratif proairetik, semantik, simbolik, dan kultural. Gejala simbolik secara sistemik dalam dinamika pertunjukan mengungkap perubahan karena proses urbanisasi, perubahan tatanan hidup sesuai hukum perubahan ruang dan waktu yang insani dan humanis. 
Nilai-nilai refleksi simbolis pada struktur pertunjukan Sandhur dibangun oleh beberapa sub-adegan. Sandhur menggugah kesadaran masyarakat pada hakikat perubahan ruang dan waktu yang dihayati sebagai kehidupan yang menyatu dengan kosmisnya. Kesejaga dan menjadi pengukuh bagi tumbuhnya seni pertunjukan yang bersifat insani dan humanis

\section{Catatan Akhir}

${ }^{1}$ Tembung Garba adalah kata yang memiliki arti dan makna yang tersirat pada pilahan kata. dalam tradisi sastra Jawa tembung garba merupakan dua kata yang diluluhkan menjadi satu kata untuk menyiratkan suatu makna.

${ }^{2}$ Migrasi penduduk merupakan peluang menyebarnya budaya kota ke desa atau sebaliknya, peralihan ini mendorong lahirnya berbagai bentuk perubahan dan pergeseran nilai dalam tatanan masyarakat. Dalam proses peralihan tersebut masyarakat desa lebih banyak menerima budaya kota sebagai budaya baru yang menawarkan kemapanan sosial.

${ }^{3}$ Gula merah dibuat dari legen/nira yaitu cairan yang disadap dari manggar enau. Manggar 'bunga enau' disadap menghasilkan legen/nira manis. Selain menghasilkan legen juga menghasilkan tuak yaitu sejenis minuman tradisional beralkohol.

${ }^{4}$ Pétung adalah system memperhitungkan keberuntungan nasib melalui neptu dina hari baik (srine dina) selalu dikaitkan dengan perkiraan naga dina, naga sasi, naga taun.

${ }^{5}$ Wilayah persebaran pertunjukan Sandhur.

${ }^{6}$ Redesain Jakarta Tata Kota Tata Kita 2020, Ahmaddin Ahmad mengatakan bahwa "daya tarik kota besar bukan hanya luasnya lapangan kerja, tetapi juga yang mencakup daya tarik romantisme dan avounturisme kota yang penuh dengan hal yang heterogen, keserbaenekaan, objek rekreasi, dan seni yang beraneka ragam".

${ }^{7}$ Pasa ngebleng adalah puasa 24 jam tidak makan dan minum. Hal ini berkaitan erat dengan penyucian diri dan konsentrasi batin untuk mencapai satu tujuan.

${ }^{8}$ Anak gembala diyakini memiliki kelebihan terhindar dari kekuatan jahat roh halus.

${ }^{9}$ Isbat merupakan filsafat hidup dituturkan dalam bentuk perumpamaan, personifikasi, simbol abstrak.

\section{Daftar Pustaka}

\section{Agus Salim}

2002 Perubahan Sosial: Sketsa Teori dan Refleksi Metodologi Kasus Indonesia. Yogyakarta: PT. Tiara Wacana Yogya.
Ahmad Ahmaddin

2002 Tata Kota Tata Kita, 2020. Jakarta: Kotakita Press.

Alex Sobur

2003 Semiotika Komunikasi. Bandung: PT. Remaja Rosdakarya.

Dillistone, F.W.

2002 The Power Of Symbols. Yogyakarta: Yayasan Kanisius

Geertz, Clifford

1981 The Religion of Java. Terjemahan Aswab Mahasin. Jakarta: Pustaka Jaya.

Hari Poerwanto

2000 Kebudayaan dan Lingkungan dalam Perspektif Antroplogi. Yogyakarta: Pustaka Pelajar.

Hauser, Arnold

1978 The Sociology of Art. Chicago: The University of Chicago Press.

Huizinga, Johan

1955 Homo Ludens: A Study of The Play-Element in Culture. Boston: Beacon Press.

Joko Susilo

2011 "Kalongking Pertunjukan Berlatar Seni Sandhur Tuban" Deskripsi Penyajian Karya Seni S2 Pascasarjana ISI Surakarta.

Kurniawan

2001 Semiologi Roland Bartesh. Yogyakarta: Yayasan Indonesiatera.

Muhammad Damami

2002 Makna Agama dalam Masyarakat Jawa. Yogyakarta: LESFI

Schechner, Richard

1988 Performance Theory. New York and London: Routledge 
Shills, Edward

1981 Tradition. Chicago: The University of Chicago Press.

Sjafri Sairin

2002 Perubahan Sosial Masyarakat Indonesia: Perspektif Antropologi. Yogyakarta: Pustaka Pelajar.
Turner, Victor

1986 The Anthropology of Performance. New York: PAJ Publications.

Yasraf Amir Piliang

2003 Hipersemiotika: Tafsir Cultural Studies atas Matinya Makna. Yogyakarta: Jalasutra. 